\title{
The target reliability and design working life
}

\author{
M. Holický \\ Klokner Institute, CTU in Prague, Czech Republic
}

\begin{abstract}
Design working life and target reliability levels recommended in various national and international documents are inconsistent. Indicative values of design working life are within a range from 10 to 100 years for different types of structures, recommended target reliability indexes are usually given for one or two reference periods ( 1 year and 50 years), without an explicit link to the design working life. The contribution attempts to clarify the relationship between the design working life and the reliability index and to provide guidance for specification of the target reliability level for given consequences, designs working life and discount rate. The theoretical study based on probabilistic optimization is supplemented by practical recommendations. It appears that the optimum reliability indexes depend primarily on the ratio of cost of structural failure (malfunctioning costs) and the cost per unit of structural parameter, less significantly on the design working life and discount rate.
\end{abstract}

Keywords: design working life, target reliability, optimisation.

\section{Introduction}

Design working life is understood as an assumed period of time for which a structure is to be used for its intended purpose without any major repair being necessary. Indicative values of design working life (10 to 100 years for different types of structures) are given in EN 1990 [1]. Recommended target reliability indexes are given for two reference periods ( 1 year and 50 years), without any explicit link to the design working life (see Table 1).

It should be underlined that a couple of $\beta$ values (for 1 year and 50 years) given in Table 1 for each reliability class corresponds to the same reliability level. Practical application of these values, however, depends on the time period considered in the verification, which may be linked to available probabilistic 
information concerning time variant basic variables (imposed load, wind, earthquake, etc.).

Table 1: $\quad$ Reliability classification in accordance with EN 1990 [1].

\begin{tabular}{|c|c|c|c|c|}
\hline $\begin{array}{c}\text { Reliability } \\
\text { classes }\end{array}$ & $\begin{array}{c}\text { Consequences } \\
\text { of structural } \\
\text { failure }\end{array}$ & \multicolumn{2}{|c|}{$\begin{array}{c}\text { Reliability index } \beta \\
\text { for reference period }\end{array}$} & $\begin{array}{c}\text { Examples of buildings } \\
\text { and civil engineering }\end{array}$ \\
\cline { 3 - 4 } & 1 year & 50 years & works \\
\hline RC3 - high & High & 5,2 & 4,3 & Bridges, public buildings \\
RC2 - & Medium & 4,7 & 3,8 & Residences and offices \\
normal & & & & \\
RC1 - low & Low & 4,2 & 3,3 & Agricultural buildings \\
\hline
\end{tabular}

For example, considering a structure of reliability class 2 and the design working life 50 years, the reliability index $\beta=3,8$ should be used provided that probabilistic models of basic variables are available for this period. The same reliability level is achieved when the reference period 1 year and $\beta=4,7$ are applied using the theoretical models for one year.

A more detail recommendation concerning is provided by ISO 2394 [2] where the target reliability indexes are indicated for the whole design working life (without any limitation) and related not only to the consequences but also to the relative costs of safety measures (see Table 2).

Table 2: $\quad$ Target reliability indexes $\beta$ (life-time, examples) in accordance with ISO 2394 [2].

\begin{tabular}{|l|c|c|c|c|}
\hline \multirow{2}{*}{$\begin{array}{l}\text { Relative costs of } \\
\text { safety measures }\end{array}$} & \multicolumn{4}{|c|}{ Consequences of failure } \\
\cline { 2 - 5 } High & small & some & moderate & great \\
\hline Moderate & 0 & 1,5 & 2,3 & 3,1 \\
\hline Low & 1,3 & 2,3 & 3,1 & 3,8 \\
\hline
\end{tabular}

Similar recommendation is provided in the JCSS Probabilistic model code [3] (Table 3). Recommended target reliability indexes are also related to both the consequences and to the relative costs of safety measures, however for the reference period 1 year. The consequences classes in [3] (similar to those in EN 1990 [1]) are linked to the ratio $\rho$ defined as the ratio between the total costs (cost of construction plus direct failure costs) and construction costs as follows:

- Class 1 Minor Consequences: $\rho$ is less than approximately 2; risk to life, given a failure, is small to negligible and economic consequences are small or negligible (e.g. agricultural structures, silos, masts);

- Class 2 Moderate Consequences: $\rho$ is between 2 and 5; risk to life, given a failure, is medium or economic consequences are 
considerable (e.g. office buildings, industrial buildings, apartment buildings);

- Class 3 Large Consequences: $\rho$ is between 5 and 10; risk to life, given a failure, is high, or economic consequences are significant (e.g. main bridges, theaters, hospitals, high rise buildings).

Table 3: $\quad$ Tentative target reliability indexes $\beta$ (and associated target failure rates) related to one year reference period and ultimate limit states in accordance with JCSS [3].

\begin{tabular}{|l|c|c|c|}
\hline $\begin{array}{c}\text { Relative costs } \\
\text { of safety } \\
\text { measures }\end{array}$ & $\begin{array}{c}\text { Minor } \\
\text { consequences of } \\
\text { failure }\end{array}$ & $\begin{array}{c}\text { Moderate } \\
\text { consequences of } \\
\text { failure }\end{array}$ & $\begin{array}{c}\text { Large } \\
\text { consequences of } \\
\text { failure }\end{array}$ \\
\hline Large & $\beta=3,1\left(p \approx 10^{-3}\right)$ & $\beta=3,3\left(p \approx 5 \times 10^{-4}\right)$ & $\beta=3,7\left(p \approx 10^{-4}\right)$ \\
\hline Normal & $\beta=3,7\left(p \approx 10^{-4}\right)$ & $\beta=4,2\left(p \approx 10^{-5}\right)$ & $\beta=4,4\left(p \approx 5 \times 10^{-6}\right)$ \\
\hline Small & $\beta=4,2\left(p \approx 10^{-5}\right)$ & $\beta=4,4\left(p \approx 5 \times 10^{-6}\right)$ & $\beta=4,7\left(p \approx 10^{-6}\right)$ \\
\hline
\end{tabular}

Both documents [2] and [3] seem to recommend the reliability indexes lower than those given in EN 1990 [1] even for the "small relative costs" of safety measures. It should be noted that EN 1990 [1] gives the reliability indexes for two reference periods 1 and 50 years that may be accepted as the design working life for common structures (see also discussion provided in [4]). ISO 2394 [2] recommends indexes for "life-time, examples", thus related to the design working life and Probabilistic Model Code [3] provides reliability indexes for the reference period of 1 year.

However, a clear link between the design working life and the target reliability level is not apparent from any of the above mentioned documents. Thus, it is not clear what the target reliability index should be used for a given design working life different from 50 years (say 10 years).

The basic aim of this contribution is to clarify the link between the design working life and the reliability index and to provide guidance for specification of the target reliability level for a given design working life. Submitted theoretical study based on probabilistic optimization is supplemented by practical recommendations.

\section{General principles of probabilistic optimization}

Probabilistic optimization is based on fundamental form of the objective function expressed as the total $\operatorname{cost} C_{\text {tot }}(x, q, n)$

$$
C_{\mathrm{tot}}(x, q, n)=C_{\mathrm{f}} \sum_{i=1}^{n} P_{\mathrm{f}}(x, i) Q(q, i)+C_{0}+x C_{1}
$$

Here $x$ denotes a decision parameter of the optimization (a parameter of structural resistance), $q$ is annual discount rate (e.g. 0,03, an average long run value of the real annual discount rate in European countries), $n$ the number of years of a considered design working life (e.g. 50, 100), $P_{\mathrm{f}}(x, i)$ failure probability 
at the year $i, C_{\mathrm{f}}$ malfunctioning costs (due to loss of structural utility), $Q(q, i)$ discount factor dependent on the annual discount rate $q$ and the number of years $i, C_{0}$ initial cost independent of decision parameter $x$, and $C_{1}$ cost per unit of the decision parameter $x$.

Note that the design working life is considered here as a given deterministic quantity characterized by the number of years $n$. In reality the working life for a given design may be a random quantity depending on social and physical factors. The design itself may aim at some optimum. This option of random design working life is, however, neglected in this study.

Assuming almost independent failure events in subsequent years, the annual probability of failure $P_{\mathrm{f}}(x, i)$ at the year $i$ is given by the geometric sequence

$$
P_{\mathrm{f}}(x, i)=p(x)(1-p(x))^{i-1}
$$

where $p(x)$ denotes the initial probability of failure that is dependent on the decisive parameter of structural resistance $x$. Note that annual failure probabilities can be assumed to be independent when failure probabilities are dominantly influenced by time-variant loads (climatic actions, traffic loads). Then the failure probability $P_{\mathrm{f} n}(x)$ during $n$ years can be estimated by the sum of the sequence $P_{\mathrm{f}}(x, i)$ given as

$$
P_{\mathrm{f} n}(x)=1-(1-p(x))^{n} \approx n p(x)
$$

Note that the approximation indicated in equation (3) is acceptable for small probability $p(x)<10^{-3}$.

The discount factor of the expected future costs at the year $i$ is considered in a usual form as

$$
Q(q, i)=1 /(1+q)^{i}
$$

Thus, the cost of malfunctioning $C_{\mathrm{f}}$ is discounted by the factor $Q(q, i)$ depending on the discount rate $q$ and the point in time (number of year $i$ ) when the loss of structural utility occurs.

Considering equations (2) and (4) the total costs $C_{\text {tot }}(x, q, n)$ described by equation (1) may be written as

$$
C_{\text {tot }}(x, q, n)=C_{\mathrm{f}} p(x) P Q(x, q, n)+C_{0}+x C_{1}
$$

Here the total sum of expected malfunction costs during the period of $n$ years is dependent on the product of the present value of malfunction cost $C_{\mathrm{f}}$, annual probability $p(x)$ and a sum of the geometric sequence having the quotient (1$p(x)) /(1+q)$, denoted as time factor $P Q(x, q, n)$ :

$$
P Q(x, q, n)=\frac{1-\left[\frac{(1-p(x))}{(1+q)}\right]^{n}}{1-\frac{(1-p(x))}{(1+q)}}
$$

In general the total cost $C_{\text {tot }}(x, q, n)$ depends on the costs $C_{0}, C_{1}, C_{\mathrm{f}}$, annual probability of failure $p(x)$, discount rate $q$ and on the number of years $n$. Note 
that for small probabilities of failure $p(x)$ (for appropriate structural parameter $x$ ) and small discount rate $q$, the time factor $P Q(x, q, n) \approx n$.

The necessary condition for the minimum of the total cost follows from (1) as

$$
\frac{\partial C_{\mathrm{tot}}(x, q, n)}{\partial x}=C_{\mathrm{f}} \sum_{i=1}^{n} Q(q, i)\left[\frac{\partial P_{\mathrm{f}}(x, i)}{\partial x}\right]_{x=x_{\mathrm{opt}}}+C_{1}=0
$$

thus

$$
\sum_{i=1}^{n} Q(q, i)\left[\frac{\partial P_{\mathrm{f}}(x, i)}{\partial x}\right]_{x=x_{\mathrm{opt}}}=-\frac{C_{1}}{C_{\mathrm{f}}}
$$

Equation (6) represents a general form of the necessary condition for the minimum of total cost $C_{\text {tot }}(x, q, n)$ and the optimum value $x_{\text {opt }}$ of the parameter $x$ and the optimum annual probability of failure $p_{\mathrm{opt}}=p\left(x_{\mathrm{opt}}\right)$. The optimum probability for the total design working life $T_{\mathrm{d}}=n$ years follows from equation (2) as

$$
P_{\mathrm{f} n, \mathrm{opt}}=1-\left(1-p_{\mathrm{opt}}\right)^{n} \approx n p_{\mathrm{opt}}
$$

The corresponding optimum reliability index $\beta_{\mathrm{opt}}=-\Phi^{-1}\left(P_{\mathrm{f} n, \mathrm{opt}}\right)$. These quantities are in general dependent on the cost ratio $C_{\mathrm{f}} / C_{1}$, discount rate $q$ and number of years $n$.

\section{Failure probability of a generic structural member}

Consider a generic structural member described by the limit state function

$$
Z(x)=x f-(G+Q)
$$

Here $x$ denotes a deterministic structural parameter (say cross-section area), $f$ strength of the material, $G$ appropriate load effect due to permanent load and $Q$ load effect due to variable load. Theoretical models of the random quantities $f, G$ and $Q$ considered in the following example are given in Table 4.

Table 4: Theoretical models of the random variables $f, G$ and $Q$ (annual extremes).

\begin{tabular}{|c|c|c|c|c|}
\hline Variables & Distribution & The mean & Standard deviation & Coef. of variation \\
\hline$f$ & Lognormal & 100 & 10 & 0,10 \\
\hline$G$ & Normal & 40 & 4 & 0,10 \\
\hline$Q$ & Gumbel & 10 & 5 & 0,50 \\
\hline
\end{tabular}

Considering the theoretical models given in Table 4 , the reliability margin $Z(x)$ may be (conservatively) approximated by a normal distribution (the coefficient of skewness is around 0,1 only). The annual failure probability $p(x)$ is then given as

$$
p(x)=\Phi_{Z(x)}(Z(x)=0)
$$


where $\Phi_{Z}(Z(x)=0)$ denotes the normal distribution of the reliability margin $Z(x)$ for $Z(x)=0$.

\section{An example}

The following example illustrates the general principles and a special case of probabilistic optimization. To simplify the analysis the total costs $C_{\text {tot }}(x, q, n)$ given by equation (1) are transformed to the standardized form $\kappa_{\mathrm{tot}}(x, q, n)$ as

$$
\kappa_{\mathrm{tot}}(x, q, n)=\frac{C_{t o t}(x, q, n)-C_{0}}{C_{\mathrm{f}}}=p(x) P Q(x, q, n)+x C_{1} / C_{\mathrm{f}}
$$

Obviously, both the costs $C_{\mathrm{tot}}(x, q, n)$ and $\kappa_{\mathrm{tot}}(x, q, n)$ achieve the minimum for the same parameter $x_{\mathrm{opt}}$.

It is assumed that the discount rate is $q=0,03$ and the design working life is $n$ $=50$ years. Under these assumptions Figure 1 shows variation of the total standardized costs $\kappa_{\text {tot }}(x, q, n)$ (given by equation (12)), and the optimum reliability index $\beta_{\mathrm{opt}}$ corresponding to the probability $P_{\mathrm{f} n, \mathrm{opt}}$ (given by equation (9)), with structural parameter $x$ for selected costs ratio $C_{\mathrm{f}} / C_{1}$. The optimum values $x_{\mathrm{opt}}(q, n)$ of the structural parameter $x$ are indicated by the dotted vertical lines.

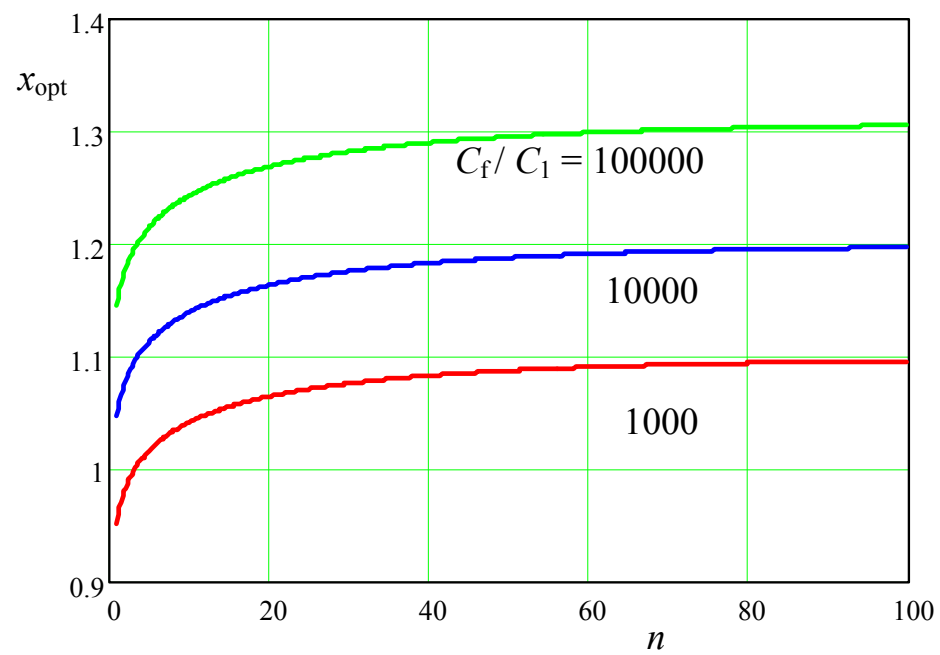

Figure 1: Variation of the total standardized costs $\kappa_{\text {tot }}(x, q, n)$ and the reliability index $\beta$ with structural parameter $x$ for $q=0,03, n=50$ and selected costs ratios $C_{\mathrm{f}} / C_{1}$.

Figure 2 shows variation of the optimum structural parameter $x_{\mathrm{opt}}(q, n)$ with the costs ratio $C_{\mathrm{f}} / C_{1}$, again for $q=0,03, n=50$. 


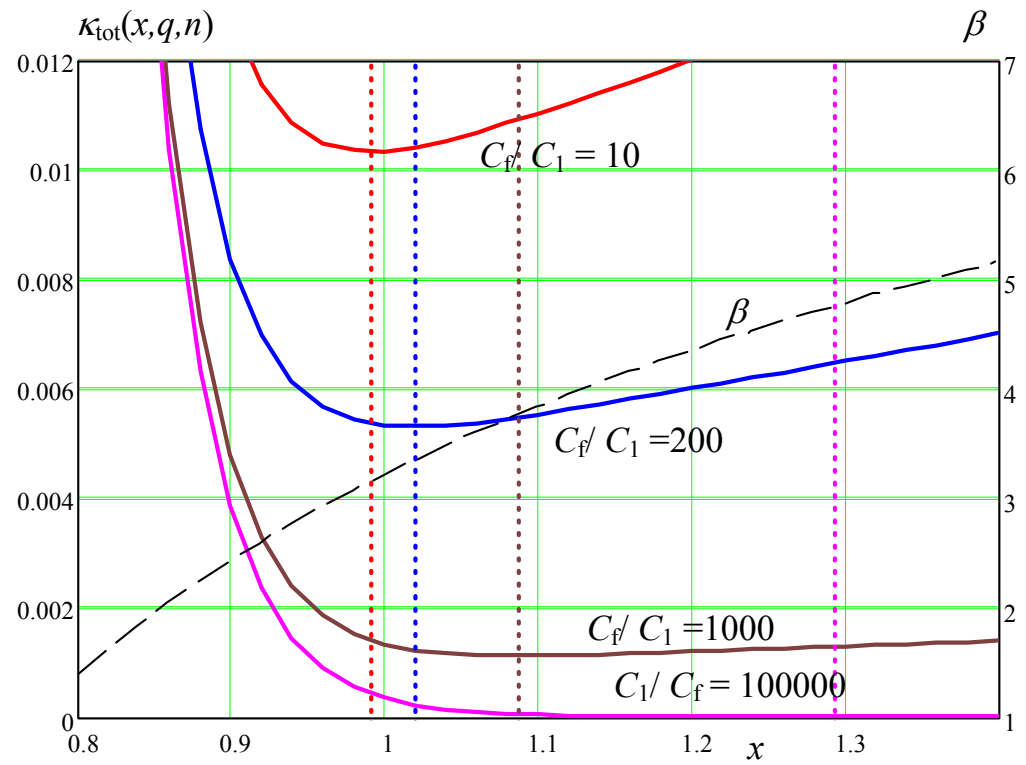

Figure 2: $\quad$ Variation of the optimum structural parameter $x_{\mathrm{opt}}$ with the life time $n$ for selected costs ratios $C_{\mathrm{f}} / C_{1}$, and the discount rate $q=0,03$.

\section{The optimum reliability index}

The optimum reliability index $\beta_{\mathrm{opt}}\left(q, n, C_{\mathrm{f}} / C_{1}\right)$ depends on the discount rate $q$, design working life $n$ and the cost ratio $C_{\mathrm{f}} / C_{1}$. However, the index $\beta_{\text {opt }}$ is primarily dependent on the cost ratio $C_{\mathrm{f}} / C_{1}$, and its dependence on the discount rate $q$ and the design working life $n$ seems to be insignificant. This is well illustrated by Figure 3 that shows variation of the optimum reliability index $\beta_{\text {opt }}$ with the cost ratio $C_{\mathrm{f}} / C_{1}$ for selected design working life $n=1,50,100$, and the discount rate $q=0,03$.

Figure 4 shows variation of the optimum reliability index $\beta_{\text {opt }}$ with the cost ratio $C_{\mathrm{f}} / C_{1}$ for discount rates $q=0,01,0,03$ and 0,05 and for the design working life $n=50$. It follows from Figures 3 and 4 that the optimum reliability index $\beta_{\text {opt }}$ slightly decreases with increasing working life $n$ and increasing discount rate $q$.

Figure 5 shows contour lines of the optimum reliability index $\beta_{\text {opt }}$ as a function of the design working life $n$ and $\operatorname{logarithm}$ of the $\operatorname{cost}$ ratio $\log \left(C_{\mathrm{f}} / C_{1}\right)$ for $q=0.03$. It can be operationally used to assess the optimum reliability index $\beta_{\text {opt }}$ for given $n$ and the cost ratio $C_{\mathrm{f}} / C_{1}$. For example, for $n=50$ and the cost ratio $C_{\mathrm{f}} / C_{1}=10000\left(\log \left(C_{\mathrm{f}} / C_{1}\right)=4\right)$, the optimum reliability index $\beta_{\text {opt }} \approx 4,3$.

The optimum $\beta_{\mathrm{opt}}$ is primarily dependent on the cost ratio $C_{1} / C_{\mathrm{f}}$, less significantly on the design working life $n$ and the discount rate $q$. 


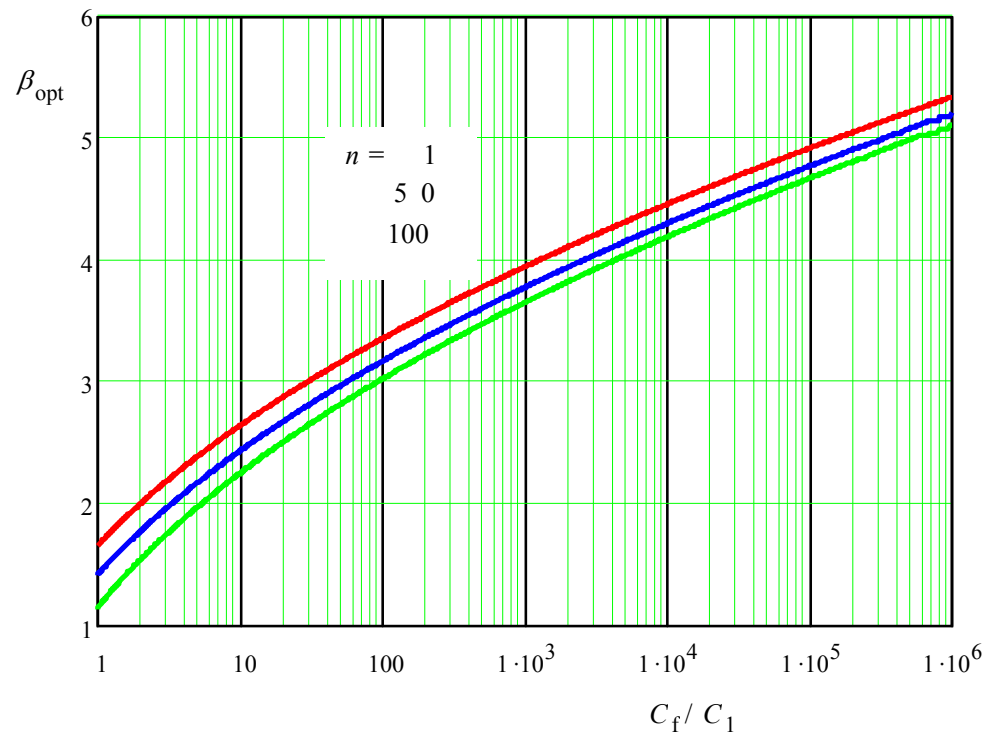

Figure 3: Variation of the optimum reliability index $\beta_{\text {opt }}$ with the cost ratio $C_{\mathrm{f}} / C_{1}$ for selected design working life $n=1,50,100$, and the discount rate $q=0,03$.

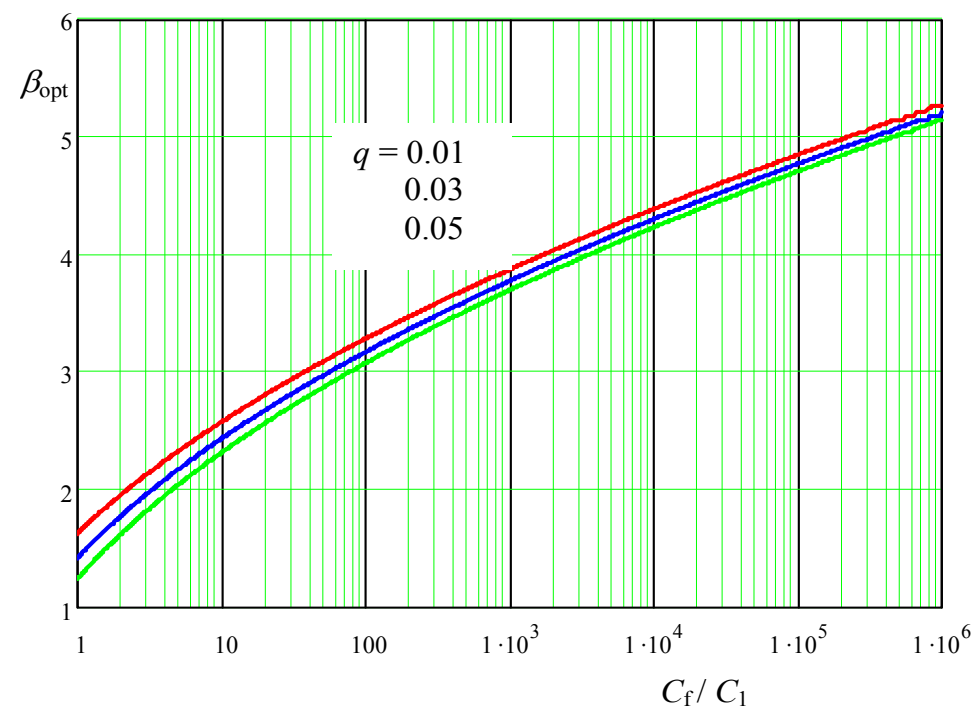

Figure 4: Variation of the optimum reliability index $\beta_{\text {opt }}$ with the cost ratio $C_{\mathrm{f}} / C_{1}$ for selected discount rates $q=0.01,0.03,0.05$, and the design working life $n=50$. 


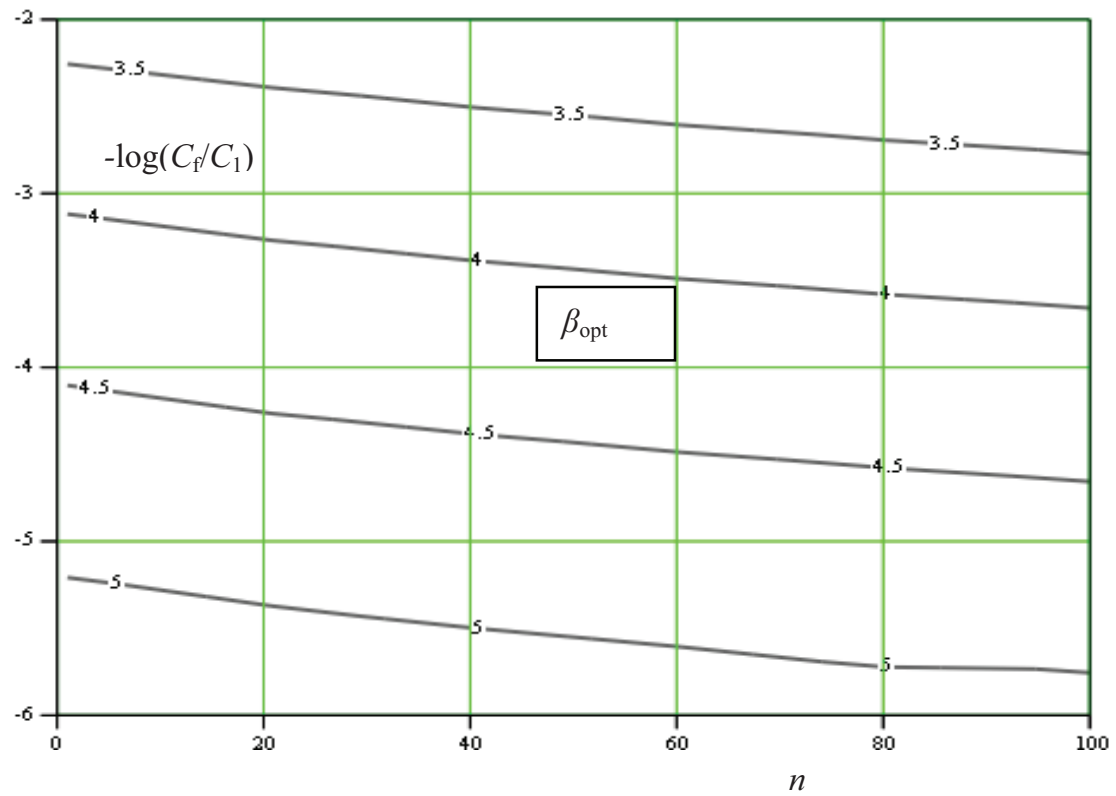

Figure 5: Contour lines of the optimum reliability index $\beta_{\mathrm{opt}}$ as a function of the design working life $n$ and the cost ratio $C_{1} / C_{\mathrm{f}}$ for the discount rate $q=0,03$.

It should be mentioned that the target reliability index $\beta_{\mathrm{t}}$ can not be chosen as the optimum reliability index $\beta_{\text {opt }}$ when the cost ratio $C_{\mathrm{f}} / C_{1}$ is unknown or difficult to assess. Then a conservative value assessed for reasonable lower bounds of the design working life (say 50 years) and the discount rate (say 0,02 ) can be used.

\section{Conclusions and recommendations}

Present documents including codes for structural design provide no clear link between the design working life and the target reliability level and no recommendations are offered to specify the target reliability index for a given design working life different from 50 years (say 10 years).

Probabilistic optimization may provide valuable background information for specification of the target probability of failure or the reliability indexes. It appears that the optimum reliability indexes depend on:

- the ratio of cost of structural failure (malfunctioning costs) and cost per unit of structural parameter,

- the design working life,

- discount rate. 
Results obtained from the analyzed example indicate more specific conclusions, validity of which should be conditioned by the accepted assumptions concerning the objective function and annual failure probability. It appears that with increasing malfunctioning cost, the optimum reliability index and the optimum structural parameter increase (Figures 1 and 2). The design working life seems to have a very limited influence on the optimum reliability (Figure 3). Even less significant seems to be effect of the discount rate (Figure 4). For practical purposes the optimum target reliability index and the corresponding structural parameter can be well assessed using Figure 5 considering reasonable lower bounds for the design working life (say 50 years) and the discount rate (say 0,02 ).

Available experience indicates that applications of the optimization approach in practice should be primarily based on properly formulated objective functions, and on credible estimates for the cost per unit of structural parameter and the cost of structural failure (malfunctioning costs).

The results of this study can be implemented in practical codified design based on the Eurocodes as follows:

- the characteristic values of the basic variables including time varying loads (wind, snow etc) may remain independent of the design working life;

- the design values are specified on the bases of appropriate reliability index assessed for given cost ratio (of malfunctioning costs and cost per unit of the structural parameter), design working life and discount rate;

- the partial factors are determined considering specified design values and unchanged characteristic values of basic variables.

Alternatively the partial factors may be kept unchanged and the characteristic values may be adjusted to achieve appropriate design value of the basic variables. However, this approach seems to be less suitable for time invariant variables. It should be stated that further investigations are planned to analyze the important aspects of reliability differentiation taking into account consequences, design working life and discount rate and to illustrate implementation of achieved results in practical design.

\section{Acknowledgement}

This study is an outcome of the research project GAČR 103//09/0693.

\section{References}

[1] EN 1990: 2002. Eurocode - Basis of structural design. CEN/TC 250, 2002.

[2] IS 2394: 1998. General principles on reliability for structures. ISO, 1998.

[3] JCSS: 2001. Probabilistic Model Code. http://www.jcss.ethz.ch/, 2001.

[4] Dimitris Diamantidis: Reliability differentiation. In.: Holicky et al.: Guidebook 1, Load effects on Buildings, CTU in Prague 2009. 